\title{
Consumer interest towards tropical fruit: factors affecting avocado fruit consumption in Italy
}

Giuseppina Migliore* ${ }^{*}$, Vittorio Farina, Salvatore Tinervia, Giovanni Matranga and Giorgio Schifani

* Correspondence: giuseppina.migliore@unipa.it Universita degli Studi di Palermo, Palermo, Italy

\begin{abstract}
The purpose of this paper is to identify the main factors affecting the consumption of avocado fruit among Italian consumers. In order to respond to the aim of the study, an empirical survey was conducted through the submission of an online questionnaire to 327 consumers. An ordered logit econometric model was adopted to examine the relationship among some explanatory variables and the frequency of consumption of avocado fruit. The findings of this study show that the consumption of avocado fruit is affected by different factors, including fruit consumption habit, neophilia attitudes, and various intrinsic and extrinsic quality attributes (credence attributes in particular). The study deals with a little explored topic; therefore, the findings contribute to fill the gap in the existent literature, inasmuch as they enrich the discussion on consumers' preference for avocado fruit. However, further comparative research is clearly needed, as well as a larger research sample, to overcome limits to the external validity of the results and to investigate the analytical effort proposed in this article.
\end{abstract}

\section{Background}

Consumer interest in tropical fruits has experienced a significant increase in Europe during the last decades, due to a greater presence of ethnic minorities, better knowledge of these fruits facilitated by the globalization phenomenon, and an increased health consciousness (Sabbe et al. 2009).

Although the consumption of several tropical fruits has grown worldwide, many of these fruits remain unknown or underutilized and are marketed only in their respective production areas (Sabbe et al. 2009; Gruère et al. 2006). This lack of familiarity with tropical fruits represents one of the main barriers for trial purchase. As emphasized by Sabbe et al. (2008, 2009), in the studies carried out on Belgian consumers, some tropical fruits are better known and more often bought than others, underlining that product familiarity is one of the most important determinants predicting purchase choice for tropical fruits. Psychological factors could have important effects on the probability to purchase tropical fruits, among them food neophobia and neophilia, described as the personality trait in relation to whether or not people enjoy trying new foods (Pliner and Hobden 1992; Ritchey et al. 2003). Consumers who have a predisposition to be neophobic seem to be reluctant to eat exotic food, such as some tropical

(c) The Author(s). 2017 Open Access This article is distributed under the terms of the Creative Commons Attribution 4.0 International License (http://creativecommons.org/licenses/by/4.0/), which permits unrestricted use, distribution, and reproduction in any medium, provided you give appropriate credit to the original author(s) and the source, provide a link to the Creative Commons license, and indicate if changes were made. 
fruits, while others have a tendency to be food neophilic, which is the tendency to seek out new tastes (Kim et al. 2009; Cohen and Avieli 2004). However, consumers do not choose tropical fruits exclusively on the basis of product familiarity or their personality. In the literature on consumer studies, it has been argued that consumer choice also depends on the level of correspondence between quality characteristics of the product and consumers' preference structures (Cardello 1995). This preference varies from consumer to consumer, and the perception of quality depends not only on the product's objective characteristics (e.g. nutritional and textural characteristics) but also on what can be defined as the result of a subjective process based on the consumer's perception of the product (Migliore et al. 2015). These quality characteristics can be categorized into intrinsic and extrinsic quality attributes. Intrinsic attributes refer to the physical characteristics of the product and are further categorized as search attributes, such as freshness, colour, and size; experience attributes, such as taste, aroma, and ripeness, identify only after consuming the product (Badar et al. 2015; Di Vita et al. 2017; Cembalo et al. 2015). Extrinsic attributes do not refer to the physical characteristics of the product, and consumers consider them increasingly important during the process of choice (Schifani et al. 2016; Migliore et al. 2015). They include food safety, environmentally friendly production, and provenance (Moor et al. 2014; Dekhili and d'Hauteville 2009). These attributes are also defined as credence attributes, as they cannot be easily determined without incurring information costs (Moser et al. 2011).

Among tropical fruits, avocado has recorded a steady growth in Italy, accompanied by an import volume that reached about 14,000 tonnes in 2016 (ISTAT 2016). In Italy, the production of avocado is limited to the Sicily region, where in recent decades a modest growth in avocado cultivation has been recorded. Although avocado fruit production is not native to the Mediterranean basin, and therefore unidentifiable as a fruit of the Italian tradition, its cultivation plays an important role in terms of diversification and innovation opportunities for the marginal Sicilian farms. Understanding consumer preference for avocado fruit may, therefore, be considered important for both producers and the agro-food industry. To the best of our knowledge, there are only two published studies on consumers' preference for avocado. These studies are delimited to ascertain the effect of maturity, the stage of ripeness, and storage damage on consumers' choice in Australia (Gamble et al. 2010) and to ascertain the general quality characteristics appreciated by American consumers (Storey et al. 1973).

The aim of this study was to understand which factors affect the consumption of avocado fruit in Italy. To achieve this research objective, 327 consumers were interviewed by means of an online questionnaire, which was designed to test the strength of factors that influence consumer choice to consume avocado fruit in Italy.

The hypothesis behind the present study is that consumers' choice is simultaneously affected by the consumption habit of respondents and by the tendency of consumers to be neophilic. Moreover, similarly to what emerges from the literature on fruit consumption, we assume that credence quality characteristics play a major role in affecting consumers' choice to consume more frequently avocado fruit. The next section is dedicated to explore the main quality characteristics of avocado fruit and its distribution in Sicily. Afterwards, we present the method and results. The findings of this study should enrich the discussion on consumers' preference for avocado fruit, 
making more accurate strategies possible when supporting the spread of avocado cultivation in those areas where the agronomic characteristics allow it.

\section{Avocado fruit: characteristics, origins and diffusion}

The avocado (Persea Americana Mill.) is a perennial evergreen tree belonging to the Laurel (Lauraceae) family. It originated in Central America and southern Mexico and is distributed throughout tropical and subtropical regions, especially Asia and America, where it is extensively cultivated including habitats from sea level to over $3000 \mathrm{~m}$ above sea level (Bernal and Díaz 2005). Spain and Italy are the only European countries with significant commercial production of avocados that are respectively cultivated in the Andalusian Mediterranean coast, mainly in the provinces of Malaga and Granada and in Sicily along the Tyrrhenian coastal areas and close to Catania (De Michele et al. 2007).

In Southern Italy, climate conditions are very favourable for avocado fruit production. In Sicily, the temperatures and the average rainfalls are characteristic of an upper thermos-Mediterranean lower sub-humid bioclimatic belt (Gianguzzi et al. 2015), and the avocado tree has shown adaptability to a wide range of ecological conditions. The orchards are mainly located along the Tyrrhenian coastal areas from the province of Palermo to the province of Messina, as well as in the Piana di Catania, mainly in the municipality of Giarre, covering a wide range of climates and soil types, from sandy loam to volcanic soils. From 1978 (Continella 1978; Calabrese et al. 1980), many cultivars were studied in Sicily with interesting results in terms of vegetative performances, yield, and fruit quality with the best observed results for Hass, Reed, and Bacon cultivars (De Michele et al. 2007). A recent study indicates that Sicilian avocado fruit is an important source of phenolic compounds, which depend on genetic differences and maturation stage (Di Stefano et al. 2017). Considering the suitability of the environment in these areas, as well as a good market trend in Europe and productive-qualitative results, avocado is grown on some farms in Sicily and its cultivation is quickly expanding in conjunction with the crisis in the citrus market. Today, Sicilian farms of all sizes have diversified into avocado fruit production. Some of these have an area of less than $1 \mathrm{ha}$, and their production is directed to the local market. Other farms have combined their orchards and developed a unique brand with the aim to reach the European market with a high-quality fruit. The estimated total area in the region is around 60 ha. The European Union is the largest importer of the fruit coming from countries such as South Africa, Chile, Israel, and Spain. Fresh avocado could be cultivated and commercialized in Mediterranean areas limiting the long-distance fruit export season from tropical countries and represents a diversification market for some fruit tree growers. Avocado is very much appreciated, and it occupies a prominent place in the market due to its high nutritional value, especially vitamins, antioxidants, fibre, fats, and low sugar content (Bergh 1990a). It is a good source of provitamin A, riboflavin, and niacin. The protein content of $1-2 \%$ is considered to be greater than in any other fresh fruit (Bergh 1990b). For this reason, it is generally recommended for diabetics since it is a high-energy food (Sinyinda and Gramshaw 1998) and can be used in a wide range of food products (Pino et al. 2001).

Relative to the quality attributes of avocado, consumers seem to be influenced by both external and internal qualities of the fruit. External qualities include fruit weight 
(commercial size), shape (oval or pyriform), skin colour (green or black), skin texture (smooth or rough), absence of defect (e.g. sunburn); whereas internal factors are flavour, flesh texture, flesh colour, and seed size (Storey et al. 1973).

\section{Methods}

In order to contribute to identifying the main factors affecting the consumption of avocado fruit in Italy, an online questionnaire survey to 327 consumers of fruits was administered between April and May 2017. Participants were recruited by snowball sampling, using social networks (Facebook and Twitter) to reach as large a number of participants as possible (Browne 2005). The questionnaire was structured in four sections. In the first section, some questions were asked about the frequency of traditional fruit consumption ${ }^{1}$ and tropical fruit consumption and the frequency of avocado consumption during the last 6 months ${ }^{2}$. The second section contained 10 items of the Food Neophobia Scale (FNS) of Pliner and Hobden (1992) opportunely adapted to exotic fruits, where consumers responded on a 7-point Likert scale from "extremely disagree" (1) to "extremely agree" (7). In the third part of the questionnaire, a first question with a dichotomous answer (Yes, No) served to understand whether respondents have ever eaten avocado. Based on the answer given, the questionnaire follows two different destinations: the first destination was dedicated to those who have consumed avocado fruit in the last 6 months, where a set of avocado fruit quality attributes were presented asking them to rate the importance of each attribute using a Likert scale ranging from 1 to 7 (where 1 was none and 7 was highly important). The second destination was dedicated to respondents who claimed to have never consumed avocado fruit, asking them to specify the reasons. Finally, the fourth section of the questionnaire included all variables concerning the socioeconomic features of the interviewee, such as age, gender, education (divided into four categories: primary school, lower secondary school, upper secondary school, university degree or higher), number of household members, and monthly household net income in euros. An ordered logit econometric model using STATA 11 software was implemented to measure the effects of quality attributes on consumer choice (Cameron and Trivedi 2005). The ordered results are modelled as a latent variable sequence, through gradually increasing threshold levels. For the $i$ th individual, it is stated that:

$$
y_{i}^{\prime}=x_{i}^{\prime} \beta+u_{i}
$$

An ordered model with $m$ alternatives may be expressed as:

$$
y_{i}=j \quad \text { if } \quad \alpha_{j-1}<y_{i}^{\prime} \leq \alpha_{j}, \quad j=1, \ldots \ldots, m
$$

where $\alpha_{0}=-\infty$ e $\alpha_{m}=\infty$.

Therefore,

$$
\begin{aligned}
& \operatorname{Pr}\left(y_{i}=j\right)=\operatorname{Pr}\left(\alpha_{j-1}<y_{i}^{*} \leq \alpha_{j}\right) \\
& =\operatorname{Pr}\left(\alpha_{j-1}<x_{i}^{\prime} \beta+u_{i} \leq \alpha_{j}\right) \\
& =\operatorname{Pr}\left(\alpha_{j-1}-x_{i}^{\prime} \beta<u_{i} \leq \alpha_{j}-x_{i}^{\prime} \beta\right) \\
& =F\left(\alpha_{j}-x_{i}^{\prime} \beta\right)-F\left(\alpha_{j-1}-x_{i}^{\prime} \beta\right)
\end{aligned}
$$

where $F$ is the cumulative distribution function of $u^{\mathrm{i}}$. The regression parameters, $\beta$, and 
the $m-1$ threshold parameters, $\alpha_{1}, \ldots . ., \alpha_{(m-1)}$, are obtained by maximizing the loglikelihood function with $p_{i j}=\operatorname{Pr}\left(y_{i}=j\right)$. In the case of the ordered logit model used, $u$ is distributed as a logistic $F(z)=e^{z} /\left(1-e^{z}\right.$ ) (Cameron and Trivedi 2005). The dependent variable was constructed as the frequency of consumption in the last 6 months and was subdivided into three categories: low, moderate, and high. The odds ratios (ORs) were also determined by measuring the changes in probability of the dependent variable following a unit change in the regressor. An additional advantage of this specification is that it can provide valuable information about the substitution pattern change among alternatives when the effect of conventions of quality is changed. Finally, the likelihood ratio (LR) test was used to verify if the model is correctly specified. The likelihood ratio test was conducted to test the hypothesis about $\beta$. In other words, the ORs serve to quantify how strongly the presence or absence of a property (say $j$ ) is associated with the presence or absence of another property (say $k$ ) in a given population. It is defined as the quotient of the ratios $(\Omega)$ :

$$
\Omega_{j k}=\frac{P\left(Y_{i}=j\right)}{P\left(Y_{i}=k\right)}
$$

\section{Results}

Of the overall 327 consumers participating in the online survey, only 260 (79.5\%) reported having consumed avocado; the rest had not consumed avocado, and specifically, about $16 \%$ stated that they did not consume avocado because they did not know the fruit, while almost 5\% did not like its taste. Regarding the 260 consumers of avocado, different categories of consumption frequencies emerge: low-avocado fruit consumption less than two times in 6 months; moderate-avocado fruit consumption between three and five times in 6 months (moderate); and high-consumption of avocado fruits over five times in 6 months $^{3}$ (Table 1 ).

In Tables 2 and 3, the main descriptive statistics of the variables used for the analysis are shown. Relative to the Food Neophobia Scale, it reports a good internal consistency of the items (Cronbach's alpha coefficient of 0.74). The explanatory variables implemented in the econometric model approximate the factors that could explain the consumption of avocado fruit in Italy (Table 3), including neophilic personality.

Among the 21 variables implemented in the model, only 13 variables were significant, such as frequency of traditional fruit consumption, frequency of tropical fruit consumption, food neophilia, taste, price, perishability, stage of ripeness, pulp creaminess, local origin, organic certification, gender, education, and income (Table 4). The food neophilia variable was constructed using the sum of the scores that consumers had

Table 1 Distribution of the three categories of avocado consumption

\begin{tabular}{llll}
\hline Categories & Frequency & Percentage & Cumulative\% \\
\hline Low & 103 & 39.62 & 39.62 \\
Moderate & 95 & 36.54 & 76.16 \\
High & 62 & 23.84 & 100 \\
Total & 260 & 100 & \\
\hline
\end{tabular}


Table 2 Descriptive statistics of the Food Neophilia Scale (FNS)

\begin{tabular}{lllll}
\hline & Average & Std. dev. & Min & Max \\
\hline I am constantly sampling new and different foods & 4.86 & 1.39 & 1 & 7 \\
I don't trust new foods & 1.93 & 1.51 & 1 & 7 \\
If I don't know what is in a food, I won't eat it & 1.48 & 0.98 & 1 & 7 \\
I like foods from different countries & 4.59 & 1.21 & 1 & 7 \\
Tropical fruits look too weird to eat & 2.16 & 2.06 & 1 & 7 \\
I am afraid to eat things I have never had before & 2.27 & 1.81 & 1 & 7 \\
I am very particular about the foods I will eat & 3.11 & 1.92 & 1 & 7 \\
I will eat almost anything & 4.89 & 1.85 & 1 & 7 \\
At dinner parties I will try a new food & 4.29 & 1.93 & 1 & 7 \\
I like to try new ethnic restaurants & 3.56 & 1.34 & 1 & 7 \\
Cronbach's alpha 0.74 & & & & \\
\hline
\end{tabular}

given to each scale, after having inverted the direction of the neophobia scores of the items in order to make them uniform.

In an ordered logit model, the signs of the estimated coefficients have to be interpreted as the variation direction of the dependent variable according to the increase in the regressor. In other words, the estimated positive coefficient indicates that as the regressor increases, the probability of being in the lowest category (low) decreases, while the probability of being in the highest value category (high) increases.

As can be seen, the latent variable frequency of avocado fruit consumption increases as the frequency of the explicative variables, tropical fruit consumption, food neophilia, the importance of taste, perishability, stage of ripeness, pulp creaminess, local origin, and organic certification increase, except for frequency of consumption of traditional fruit and price. Regarding the demographic characteristics, only gender, education, and income are statistically significant, showing that

Table 3 Descriptive statistics of the variables implemented in the model

\begin{tabular}{lllll}
\hline & Average & Std. dev. & Min & Max \\
\hline Frequency of traditional fruit consumption & 3.39 & 1.63 & 0 & 5 \\
Frequency of tropical fruit consumption & 2.24 & 1.52 & 0 & 4 \\
Processed fruit & 0.43 & 0.50 & 0 & 1 \\
Taste & 5.34 & 1.80 & 1 & 7 \\
Price & 4.64 & 1.73 & 1 & 7 \\
Convenience of consumption & 4.91 & 1.79 & 1 & 7 \\
Health benefits & 5.08 & 1.72 & 1 & 7 \\
Appearance (attractiveness) & 4.12 & 1.85 & 1 & 7 \\
Perishability & 4.52 & 1.89 & 1 & 7 \\
Stage of ripeness (unripe) & 5.17 & 1.67 & 1 & 7 \\
Pulp creaminess (texture) & 5.09 & 1.65 & 1 & 7 \\
Local origin & 4.51 & 2.00 & 1 & 7 \\
Organic certification & 4.66 & 1.94 & 1 & 7 \\
Seasonality & 4.56 & 1.94 & 1 & 7 \\
Visual integrity (bruising) & 5.21 & 1.81 & 1 & 7 \\
\hline
\end{tabular}


Table 4 Results of the ordered logistic regression

\begin{tabular}{|c|c|c|c|c|c|c|}
\hline \multicolumn{4}{|l|}{ Ordered logistic regression } & \multicolumn{3}{|c|}{ Number of obs $=260$} \\
\hline \multirow{2}{*}{\multicolumn{4}{|c|}{ Log likelihood = $=-300.72018$}} & \multicolumn{3}{|c|}{$\operatorname{LR~chi~}^{2}(23)=211.74$} \\
\hline & & & & \multicolumn{3}{|c|}{ Pseudo $R^{2}=0.2604$} \\
\hline Frequency of avocado consumption & Coef. & Std. err. & $z$ & $P>|z|$ & {$[95 \%$ con } & terval] \\
\hline $\begin{array}{l}\text { Frequency of traditional fruit } \\
\text { consumption }\end{array}$ & -0.1496 & 0.0847 & -1.77 & 0.077 & -0.3157 & 0.0164 \\
\hline $\begin{array}{l}\text { Frequency of tropical fruit } \\
\text { consumption }\end{array}$ & 1.2212 & 0.1195 & 10.22 & 0.000 & 0.9870 & 1.4555 \\
\hline Neophilia/neophobia & 1.0121 & 0.0145 & 0.83 & 0.004 & -0.0163 & 0.0405 \\
\hline Processed fruit & -0.1437 & 0.2711 & -0.53 & 0.596 & -0.6751 & 0.3877 \\
\hline Taste & 0.2429 & 0.1036 & 2.34 & 0.019 & 0.0398 & 0.4460 \\
\hline Price & -0.2110 & 0.1017 & -2.08 & 0.038 & -0.4102 & -0.0118 \\
\hline Convenience of consumption & 0.1080 & 0.1219 & 0.89 & 0.375 & -0.1308 & 0.3469 \\
\hline Health benefits & -0.0064 & 0.1274 & -0.05 & 0.960 & -0.2561 & 0.2433 \\
\hline Appearance (attractiveness) & 0.0347 & 0.1054 & 0.33 & 0.742 & -0.1718 & 0.2412 \\
\hline Perishability & 0.2463 & 0.0904 & 2.72 & 0.006 & 0.0691 & 0.4235 \\
\hline Stage of ripeness (unripe) & 0.8035 & 0.1437 & -2.81 & 0.005 & -0.6852 & -0.1217 \\
\hline Pulp creaminess (texture) & 0.3091 & 0.1409 & 2.19 & 0.028 & 0.0329 & 0.5853 \\
\hline Local origin & 0.0172 & 0.0996 & 0.17 & 0.063 & -0.1780 & 0.2125 \\
\hline Organic certification & 0.0045 & 0.1184 & 0.04 & 0.070 & -0.2366 & 0.2276 \\
\hline Seasonality & 0.0192 & 0.1142 & 0.17 & 0.866 & -0.2046 & 0.2430 \\
\hline Visual integrity (bruising) & 0.0080 & 0.0932 & 0.09 & 0.932 & -0.1747 & 0.1907 \\
\hline Age & -0.0006 & 0.0104 & -0.06 & 0.956 & -0.0210 & 0.0198 \\
\hline Gender & 0.7099 & 0.2591 & 2.74 & 0.006 & 0.2021 & 1.2176 \\
\hline Education & 0.2072 & 0.1844 & 1.12 & 0.061 & -0.1541 & 0.5685 \\
\hline Living in a urban area & -0.4226 & 0.2868 & -1.47 & 0.141 & -0.9847 & 0.1395 \\
\hline Income & 0.2003 & 0.0731 & 2.74 & 0.006 & 0.0570 & 0.3435 \\
\hline /cut1 & 3.0720 & 1.1812 & & & 0.7570 & 5.3870 \\
\hline /cut2 & 4.5396 & 1.1946 & & & 2.1982 & 6.8810 \\
\hline
\end{tabular}

the latent variable, frequency of avocado consumption, increases as these demographic variables increase in value (Table 4).

The threshold parameters ( 1 and 2 ) are both statistically and significantly different from each other so as to indicate that the dependent variable is well represented by the three categories.

The odds ratios (ORs) were also determined by measuring the change in probability of the dependent variable following a unit variation in the regressor. When the OR is equal to 1 , the effect of the unit variation of the regressor on the dependent variable is null. Holding the values of the other explanatory variables constant, the larger the deviation from the unit value, the greater the effect of the regressor on the dependent variable. The regressors with the greatest effect on the frequency of avocado consumption are frequency of tropical fruit consumption and gender, where being female increases the probability of consuming avocado fruit more frequently. Among the quality characteristics of avocado fruit, local origin and organic certification have the greatest effect 
on the probability of having a high frequency of consumption (about 1.5 times, respectively-Table 5).

\section{Discussion}

The findings of this study show that the consumption of avocado fruit is affected by different factors. Specifically, the frequency of consumption of avocado is negatively affected by the frequency of traditional fruit consumption and positively by the frequency of tropical fruit consumption. This finding highlights that consumption habits show an important role; in fact, a high frequency of avocado consumption usually occurred in those consumers who frequently eat tropical fruits and less traditional fruits. Moreover, the high frequency of avocado fruit consumption is affected by those personality traits inclining to be food neophilic, which is the tendency to seek to taste something new. In this study, many of the factors affecting consumer choice deal with the consumer's perception of some quality attributes. In particular, a major effect is shown by two credence attributes,

Table 5 Odds ratio calculated on the results of ordered logistic regression

\begin{tabular}{|c|c|c|c|c|c|c|}
\hline \multicolumn{4}{|l|}{ Ordered logistic regression } & \multicolumn{3}{|c|}{ Number of obs $=260$} \\
\hline \multicolumn{4}{|l|}{ Log likelihood $=-300.72018$} & \multicolumn{3}{|c|}{ Pseudo $R^{2}=0.2604$} \\
\hline Frequency of avocado consumption & Odds ratio & Std. err. & $z$ & $P>|z|$ & {$[95 \%$ co } & interval] \\
\hline Frequency of traditional fruit consumption & 0.8610 & 0.0729 & -1.77 & 0.077 & 0.7293 & 1.0165 \\
\hline Frequency of tropical fruit consumption & 3.3914 & 0.4054 & 10.22 & 0.000 & 2.6831 & 4.2867 \\
\hline Food neophilia & 1.3122 & 0.0147 & 0.83 & 0.004 & 0.9838 & 1.0413 \\
\hline Processed fruit & 0.8662 & 0.2348 & -0.53 & 0.596 & 0.5091 & 1.4736 \\
\hline Taste & 1.2750 & 0.1321 & 2.34 & 0.019 & 1.0406 & 1.5621 \\
\hline Price & 0.8098 & 0.0823 & -2.08 & 0.038 & 0.6635 & 0.9883 \\
\hline Convenience of consumption & 1.1141 & 0.1358 & 0.89 & 0.375 & 0.8774 & 1.4146 \\
\hline Health benefits & 0.9936 & 0.1266 & -0.05 & 0.960 & 0.7740 & 1.2754 \\
\hline Appearance & 1.0353 & 0.1091 & 0.33 & 0.742 & 0.8422 & 1.2728 \\
\hline Perishability & 1.2793 & 0.1157 & 2.72 & 0.006 & 1.0715 & 1.5273 \\
\hline Stage of ripeness (unripe) & 1.3680 & 0.0960 & -2.81 & 0.005 & 0.5040 & 0.8854 \\
\hline Pulp creaminess (texture) & 1.3622 & 0.1920 & 2.19 & 0.028 & 1.0335 & 1.7956 \\
\hline Local origin & 1.5174 & 0.1013 & 0.17 & 0.063 & 0.8369 & 1.2367 \\
\hline Organic certification & 1.4955 & 0.1179 & 0.04 & 0.070 & 0.7893 & 1.2556 \\
\hline Seasonality & 1.0194 & 0.1164 & 0.17 & 0.866 & 0.8150 & 1.2751 \\
\hline Peel integrity (bruising) & 1.0080 & 0.0940 & 0.09 & 0.932 & 0.8397 & 1.2100 \\
\hline Age & 0.9994 & 0.0104 & -0.06 & 0.956 & 0.9793 & 1.0200 \\
\hline Gender & 2.0337 & 0.5269 & 2.74 & 0.006 & 1.2240 & 3.3791 \\
\hline Education & 1.2302 & 0.2268 & 1.12 & 0.061 & 0.8571 & 1.7657 \\
\hline Living in urban area & 0.6553 & 0.1879 & -1.47 & 0.141 & 0.3736 & 1.1497 \\
\hline Income & 1.2217 & 0.0893 & 2.74 & 0.006 & 1.0587 & 1.4099 \\
\hline /cut1 & 3.0720 & 1.1812 & & & 0.7570 & 5.3870 \\
\hline /cut2 & 4.5396 & 1.1946 & & & 2.1982 & 6.8810 \\
\hline
\end{tabular}


such as local origin and organic certification, highlighting that consumers assign a high level of importance to these attributes when they decide to consume avocado with high frequency. This finding is in line with other studies, showing that the origin of the products is important to infer food quality. Knowledge about products' origin is a factor that can potentially modify a consumer's evaluation and perception of such products (Gázquez-Abad et al. 2012). The literature indicates that consumers consider local origin to be synonymous of high quality, although this can change in relation to both the product considered and the geographical context (Moor et al. 2014; Papanagiotou et al. 2013; Font et al. 2011; Dekhili and d'Hauteville 2009; Ekelund et al. 2007). According to the literature, organic certification is also considered an important predictor of consumers' choice. The results of numerous empirical studies show the existence of a positive cause-effect relationship between production processes and perceived effects on the environment. This is the case for organic food products, which the consumer associates with natural processes and the non-use of pesticides and fertilizers (Shafie and Rennie 2012), all of which have a positive effect on environmental sustainability (Kutnohorská and Tomšík 2013; Baker et al. 2004; Padel and Foster 2005; Zanoli and Naspetti 2002).

Other fruit quality characteristics are perishability it may be emphasized that consumers assigned a high level of importance to this attribute when they purchase avocado because this fruit is characterized by a high perishability; stage of ripeness, which shows an effect of about 1.4 times the probability to consume avocado with a high frequency and it is related to the importance of the avocado being unripe at the point of purchase; and pulp creaminess, which shows an effect of almost 1.4 times on the consumption of avocado. This is in line with the literature on avocado consumption, where it has been found that the stage of ripeness at which the fruit is consumed can affect eating quality, primarily through flesh firmness and "creaminess" texture. Consumers who tasted avocados that were in the "Firm" category were significantly less liked to be purchased than fruit that were in the "Medium" and "Soft" firmness categories (Gamble et al. 2010). Similarly to other studies, taste is also considered an important quality element that has a positive and significant influence on consumers' buying intentions. For fruit and vegetables, taste is the most important attribute consumers take into account, independent of age, gender, or the number of fruits consumed per week (Moor et al. 2014; Péneau et al. 2006; Jönson 2004). Finally, price is considered important in affecting consumer choice; on the one hand, it is perceived as a signal to infer food quality (Röhr et al. 2005), and on the other hand, it represents a barrier. In the present study, price has a negative effect on the probability of consuming avocado with a high frequency. Similarly to Sabbe et al. (2009), price plays an important role when purchasing tropical fruits, although the purchase frequency seems to occur more occasionally, emphasizing how price will even become a more limitative factor when tropical fruits have become part of a more regular purchase routine. Health benefits, peel integrity, and convenience of consumption are quality attributes considered important in affecting consumer choice. In the present study, they are not statistically significant in explaining the high frequency of avocado fruit consumption because almost all consumers surveyed stated a high level of 
importance for these attributes. Also, seasonality is among the quality attributes that show no effect on consumer choice, and it may be due to the low knowledge that consumers usually have about tropical fruits. Finally, the variable "processed fruit" also showed no effect on consumer's choice, highlighting how for the consumers surveyed eating fresh or processed avocado did not make a difference on the probability of consuming avocado fruit with a high frequency.

Regarding demographic characteristics, no differences emerge between consumers living in urban or in rural areas and among consumer age; this is in contrast, to some extent, with Sabbe and colleagues' (2008) results, who found that older consumers and those living in urban areas showed higher familiarity with fresh and processed tropical fruits. Moreover, in the present study, among the demographic characteristics, only gender, education, and income show an influence on the probability to consume avocado more frequently, emphasizing how higher educated consumers and those with a high level of income tend to consume avocado fruit more frequently. Regarding gender, similarly to Sabbe and colleagues' (2008) findings, our study showed that women tend to have more familiarity with tropical fruits and, as a result, consume avocado fruit in higher frequency.

\section{Conclusion}

The findings of the present study should enrich the discussion on consumers' preferences for avocado fruit, making more accurate strategies possible when supporting the distribution of avocado cultivation where agronomic conditions allow it. However, further comparative research is clearly needed, as well as a larger research sample, to overcome limits to the external validity of the results and to investigate the analytical effort proposed in this article. Moreover, further research effort should be directed at better understanding whether situational or cultural factors have an effect on consumers' choice of avocado fruits. Finally, future research should incorporate different behavioural theories to better understand the complex and multifaceted issue of consumer choice, also with a functional study to validate or overturn the findings obtained through the present study.

\section{Endnotes}

${ }^{1}$ In this study, by traditional fruits, we mean fruits of Mediterranean origins.

${ }^{2}$ This time interval has been chosen because the availability of avocado fruit on the market is mainly concentrated between the months of October and March.

${ }^{3}$ This frequency was chosen by asking a sample of 15 avocado fruit consumers how many times they consumed avocado during the period in which the fruit is on the market.

GM conceived of the study and carried out the introduction and results sections. VF carried out the Avocado fruit: characteristics, origins and diffusion section; ST carried out the methodological aspects section; GM partecipated to the questionnaire development and carried out data collection; GS carried out the conclusion section. All authors read and approved the final manuscript. 


\section{Publisher's Note}

Springer Nature remains neutral with regard to jurisdictional claims in published maps and institutional affiliations.

Received: 3 August 2017 Accepted: 20 November 2017

Published online: 06 December 2017

\section{References}

Badar H, Ariyawardana A, Collins R (2015) Capturing consumer preferences for value chain improvements in the mango industry of Pakistan. International Food and Agribusiness Management Review 18(3):131-148

Baker S, Thompson KE, Engelken J (2004) Mapping the values driving organic food choice: Germany vs the UK. Eur J Mark 38(8):995-1012

Bergh B (1990a) The avocado and human nutrition, I. Some human health aspects of the avocado. In: Proceedings of the 2nd World Avocado Congress, Vol I. University of California, Riverside, pp 25-35

Bergh B (1990b) The avocado and human nutrition, Il. Avocado and your heart. In: Proceedings of the 2nd World Avocado Congress, Vol I. University of California, Riverside, pp 37-47

Bernal EJA, Díaz CA (2005) Tecnología para el cultivo del aguacate Manual técnico 5 Corporación Colombiana de Investigación Agropecuaria (CORPOICA). Centro de Investigación La Selva, Rionegro

Browne K (2005) Snowball sampling: using social networks to research non-heterosexual women. Int J Soc Res Methodol 8(1):47-60

Calabrese F, De Michele A, Alliata V, Petronici C (1980) Osservazioni sul comportamento di alcune cultivar di avocado in Sicilia. Frutticoltura XLII(10-11):25-30

Cameron AC, Trivedi PK (2005) Microeconometrics: methods and applications. Cambridge University Press, New York

Cardello AV (1995) Food quality: relativity, context and consumer expectations. Food Qual Prefer 6(3):163-170

Cembalo L, Lombardi A, Pascucci S, Dentoni D, Migliore G, Verneau F, Schifani G (2015) "Rationally local": consumer participation in alternative food chains. Agribusiness 31(3):330-352

Cohen E, Avieli N (2004) Food in tourism attraction and impediment. Ann Tour Res 31(4):755-778

Continella G (1978) La coltura dell'avocado (Persea gratissima Gaertn): primi risultati ottenuti in Sicilia. Tecnica agricola $30: 63$

De Michele A, Calabrese F, Barone F, Peri G (2007) Avocado, quali varietà scegliere per sviluppare la coltivazione in Sicilia. Frutticoltura 69(1):30-33

Dekhili S, d'Hauteville F (2009) Effect of the region of origin on the perceived quality of olive oil: an experimental approach using a control group. Food Qual Prefer 20:525-532

Di Stefano V, Avellone G, Bongiorno D, Indelicato S, Massenti R, Lo Bianco R (2017) Quantitative evaluation of the phenolic profile in fruits of six avocado (Persea americana) cultivars by ultra-high-performance liquid chromatography-heated electrospray-mass spectrometry. Int J Food Prop 20(6):1302-1312

Di Vita G, Bracco S, D'Amico M (2017) Mapping the Italian cured meats' attributes: a qualitative approach. Quality-Access to Success:18

Ekelund L, Fernqvist F, Tjarnemo H (2007) Consumer preferences for domestic and organically labeled vegetables in Sweden. Food Economics 4(1):229-236

Farah Ayuni Shafie, Denise Rennie, (2012) Consumer Perceptions Towards Organic Food. Procedia - Social and Behavioral Sciences 49:360-367.

Font I, Furnols M, Realini C, Montossi F, Sañudo C, Campo MM, Oliver MA, Nute GR, Guerrero L (2011) Consumer's purchasing intention for lamb meat affected by country of origin, feeding system and meat price: a conjoint study in Spain, France and United Kingdom. Food Qual Prefer 22(1):443-451

Gamble J, Harker FR, Jaeger SR, White A, Bava C, Beresford M, Woolf A (2010) The impact of dry matter, ripeness and internal defects on consumer perceptions of avocado quality and intentions to purchase. Postharvest Biol Technol 57(1):35-43

Gázquez-Abad JC, Jiménez-Castillo D, Marín-Carrillo GM (2012) Sinergias entre los atributos del producto y la familiaridad con su origen Efectos sobre la imagen percibida. Cuadernos de Economía y Dirección de la Empresa 15(2):73-83

Gianguzzi L, Papini F, Cusimano D (2015) Phytosociological survey vegetation map of Sicily (Mediterranean region). Journal of Maps 12(5):845-851

Gruère G, Giuliani A, Smale M (2006) Marketing underutilised plant species for the benefit of the poor: a conceptual framework. EPT Discussion paper 154 IFPRI, Washington, DC

ISTAT (2016) Rapporto annuale 2016 [available on http//www.istatit/it]

Jönson AH (2004) Consumer evaluation of scab resistant apple cultivars. Acta Hortic 663:875-878

Kim YG, Eves A, Scarles C (2009) Building a model of local food consumption on trips and holidays: a grounded theory approach. Int J Hosp Manag 28(3):423-431

Kutnohorská O, Tomšík P (2013) Consumers' perception of the health aspects of organic food. Agricultural Econonomics - Czech 59(7):293-299

Migliore G, Galati A, Romeo P, Crescimanno M, Schifani G (2015) Quality attributes of cactus pear fruit and their role in consumer choice: the case of Italian consumers. Br Food J 117(6):1637-1651

Moor U, Moor A, Põldma P, Heinmaa L (2014) Consumer preferences of apple in Estonia and changes over five years. Agric Food Sci 23:135-145

Moser R, Raffaelli R, Thilmany-McFadden D (2011) Consumer preferences for fruit and vegetable with credence-based attributes: a review. International Food and Agribusiness Management Review 14(2):121-142

Padel S, Foster C (2005) Exploring the gap between attitudes and behaviour: understanding why consumers buy or do not buy organic food. Br Food J 107(8):606-625

Papanagiotou P, Tzimitra-Kalogianni I, Melfou K (2013) Consumers' expected quality and intention to purchase high quality pork meat. Meat Sci 93(3):449-454

Péneau S, Hoehn E, Roth H-R, Escher F, Nuessli J (2006) Importance and consumer perception of freshness of apples. Food Qual Prefer 17(1-2):9-19 
Pino JA, Marbot R, Vazquez C (2001) Characterization of volatiles in strawberry guava ( Sabine) fruit. Psidium cattleianum. J Agric Food Chem 49(12):5883-5887.

Pliner P, Hobden K (1992) Development of a scale to measure the trait of food neophobia in humans. Appetite 19:105-120 Ritchey PN, Frank RA, Hursti U, Tuorila H (2003) Validation and cross-national comparison of the food neophobia scale (FNS) using confirmatory factor analysis. Appetite 40:163-173

Röhr A, Lüddecke K, Drusch S, Müller MJ, Alvensleben RV (2005) Food quality and safety--consumer perception and public health concern. Food Control 16(8):649-655

Sabbe S, Van Damme P, Verbeke W (2009) Perceived motives, barriers and role of labeling information on tropical fruit consumption: exploratory findings. J Food Prod Mark 15(2):119-138

Sabbe S, Verbeke W, Van Damme P (2008) Familiarity and purchasing intention of Belgian consumers for fresh and processed tropical fruit products. Br Food J 110(8):805-818

Schifani G, Romeo P, Guccione GD, Schimmenti E, Columba P, Migliore G (2016) Conventions of quality in consumer preference toward local honey in southern Italy. Quality-Access to Success 17(153):92

Sinyinda S, Gramshaw JW (1998) Volatiles of avocado fruit. Food Chem 62(4):483-487.

Storey WB, Bergh BO, Whitsell RH (1973) Factors affecting the marketability of avocado fruit. California Avocado Society Yearbook 57:33-39

Zanoli R, Naspetti S (2002) Consumer motivations in the purchase of organic food: a means-end approach. Br Food J 104(8):643-653

Submit your manuscript to a SpringerOpen ${ }^{\circ}$ journal and benefit from:

- Convenient online submission

- Rigorous peer review

- Open access: articles freely available online

- High visibility within the field

Retaining the copyright to your article

Submit your next manuscript at $\gg$ springeropen.com 